\title{
$\$$ Research Square \\ Effect of different bonding techniques on marginal adaptation of Harmonize composite resin at different storage times.
}

Ebaa Ibrahim Alagha ( $\sim$ drebaaialagha@gmail.com )

Al-Farabi College https://orcid.org/0000-0002-1532-0344

\section{Research article}

Keywords: Adhesive system, Composite resin, Storage time

Posted Date: July 14th, 2020

DOI: https://doi.org/10.21203/rs.3.rs-35937/v1

License: (c) (1) This work is licensed under a Creative Commons Attribution 4.0 International License.

Read Full License

Version of Record: A version of this preprint was published at Journal of Pharmacy And Bioallied Sciences on January 1st, 2021. See the published version at https://doi.org/10.4103/jpbs.JPBS_564_20. 


\section{Abstract \\ Background}

This study evaluated the effect of different bonding techniques on marginal adaptation of Harmonize composite resin at different storage times.

\section{Methods}

Hundred twenty upper premolars were divided into two main groups $(n=60)$ according to the type of the adhesive system used (self-etch adhesive system or total etch adhesive system). Each group was further divided into three subgroups (20 teeth each) according to the storage times into one day, three months and six months. Standardized Class II cavities were prepared and restored with Harmonize composite incrementally. Teeth were stored in distilled water at room temperature. After each storage time, teeth were sectioned buccolingually into two halves and examined under digital stereomicroscope for the purpose of gap formation detection and scanning electron microscope examination was done to evaluate resin-dentin interfaces. The recorded values were tabulated and statistically analyzed. Regression model using three-way Analysis of Variance (ANOVA) was used for testing significance of the effect of adhesive system, storage period and their interactions on the mean gap area. Tukey's post-hoc test was used for pair-wise comparisons between the groups when ANOVA test is significant. The significance level was set at $\mathrm{P} \leq 0.05$.

\section{Results}

Self-etch adhesive system showed statistically significant higher mean gap area than Total-etch adhesive system at the occlusal and cervical margins. Six months period showed the statistically significant highest mean gap area. There was no statistically significant difference between 1 day and 3 months periods; both showed the statistically significant lowest mean gap area values respectively at the occlusal and cervical margins.

\section{Conclusions}

Total-etch adhesive system enhances the marginal adaptation when compared to self-etch adhesive system and the storage period of composite resin in water has adverse effect on the marginal adaptation to all groups with time.

\section{Background:}

Composite resins have become the first choice for direct restorations. This great popularity related to their esthetic appearance and reduced need of sound tissue removal when compared to other restorations. ${ }^{(1)}$ 
Multiple techniques were proposed to overcome the challenges during class II composite resin placement. Microleakage may occur at the gingival margin of the proximal surfaces of class II composite resin restorations due to polymerization shrinkage and gap formation at the interface between the tooth structure and the restoration which influences the bond strength between the materials and tooth. ${ }^{(2)} \mathrm{A}$ uniform interface between the tooth and restorative material is required to seal the margins and increase the durability of restoration. Obtaining such an interface is challenging in class II composite restorations.

(3) adhesive systems played a major role in improving the marginal adaptation and decreasing the magnitude of polymerization shrinkage of the composite resin restoration. ${ }^{(4)}$ Different types of the adhesive systems were developed in the dental market to simplify their clinical use. ${ }^{(5)}$ Recently, a new two-step adhesives: total-etch or self-etch, and one step adhesives which is also known as all-in-one adhesives replaced the three step adhesive systems. ${ }^{(4)}$

\section{Methods:}

A total of 120 upper premolar teeth were extracted for periodontal or orthodontic reasons were included in this study. Ethics approval was obtained from the Research Ethical Committee, Al-Farabi Private Colleges in Jeddah-KSA (Approval No20-03/8). Teeth were randomly divided into two main groups of 60 teeth each, according to the adhesive system used $(n=60)$; either total-etch bonding system $(A)$ or self-etch bonding system (B). Class II cavity was prepared in each tooth. The cervical margin of the cavity was located $1 \mathrm{~mm}$ occlusal to the cemento-enamel junction. Cavities were prepared using parallel sides, flat end with round edges diamond stone (komet, Lemgo, Germany) of size $0.10 \mathrm{~mm}$ and length $4 \mathrm{~mm}$ with high speed hand piece under water cooling. The stone was replaced every five cavity preparations. The occlusal box had buccolingual width of $3 \mathrm{~mm}$ and pulpal floor depth of $2.5 \mathrm{~mm}$ measured from the central pit. The proximal box had buccolingual width of $3 \mathrm{~mm}$ and gingival floor width of $1.5 \mathrm{~mm}$ from the enamel. The cavity margins were prepared to be butt joint. The cavity depth was standardized by making a colour mark onto the shaft of the bur used at $2.5 \mathrm{~mm}$ length. A periodontal probe was used to measure the width and depth of the cavities to ensure uniformity among preparations. ${ }^{(6)}$ The adhesive systems and restorative materials were applied into the cavities according to the manufacturer instruction. In the first group (A1), the dentin surface was etched with $37.5 \%$ phosphoric acid gel(Kerr etchant gel) for 15 seconds, rinsed with water for 15 seconds and excess water was then removed with gentle stream of air free of water or oil, then two coats of the total etch adhesive (OptiBond Solo Plus) were applied on the etched dentin surface using a fully saturated microbrush with slight agitation to cover the entire surface and gently air dried approximately $0.5 \mathrm{~mm}$ away from the prepared surface for 3 seconds to allow the solvent to evaporate. Then the adhesive light cured for 20 seconds with led lightcuring unit (Woodpecker Curing Light LED D) with narrow spectrum of blue light in the 400- to 500-nm range (with a peak wavelength of about $460 \mathrm{~nm}$ ). In the second group (A2), self-etch adhesive system (OptiBond All-In-One) was applied similarly, using a fully saturated microbrush with slight agitation to cover the entire surface and was gently air dried approximately $0.5 \mathrm{~mm}$ away from the prepared surface for 3 seconds, to allow solvent to evaporate. All prepared cavities were packed gently with two increments of the composite resin (Harmonize) by using a Teflon instrument. Each increment was light cured for 20 
seconds then a fine finishing tapered stone was used with low speed to remove the excess at the restoration margins under water coolant immediately after curing. The teeth were then stored in distilled water at $37^{\circ} \mathrm{C}$ in an incubator with 100\% humidity at different storage periods (24 hours, 3 months, 6 months). Each group was stored in a separate incubator with an assigned label. To simulate the temperature changes that take place in the oral cavity, the specimens were subjected to thermocycling between $\left(5^{\circ} \mathrm{C}-55^{\circ} \mathrm{C}\right) 1 \mathrm{~min}$ for each, for 2000 cycles. ${ }^{(7)}$ At the end of the aging period of each group, teeth were removed from the water and dried with oil free compressed air then coated with 2 layers of clear nail varnish except for the restoration and one millimeter all around the margins of the cavity to ensure complete sealing of all other surfaces of the tested specimens and left to dry completely. The crown and the root of all teeth also coated with green stick compound except for the restoration and one millimeter all around the margins of the cavity. Specimens were immersed in a freshly prepared $2 \%$ aqueous methylene blue dye solution ( $\mathrm{Ph} 7.0$ ) at $37^{\circ} \mathrm{C}$ for 24 hours. After removal from the dye solution, they were thoroughly washed under tap water and mounted and sectioned mesiodistally into two halves along their long axis ${ }^{(8)}$ through the middle of the restoration using a fine diamond disc at low speed under sufficient coolant to avoid overheating of the restoration. Both tooth halves were examined under stereo microscope (Scope Capture Digital Microscope, Guangdong, China) at X 50 magnification and photographs of specimens were taken by a digital camera connected to the stereomicroscope. For each tooth halves, the extent of leakage at the occlusal and the gingival margins were evaluated and the microleakage was assessed by scoring the degree of dye penetration in the tooth restoration interface according to the following criteria:(6) table (1)

\section{Table (1)}

Dye penetration criteria

\begin{tabular}{|ll|}
\hline Score & Dye penetration \\
\hline $\mathbf{0}$ & No dye penetration. \\
\hline $\mathbf{1}$ & Dye penetration into half of the enamel. \\
\hline $\mathbf{3}$ & Dye penetration into more of the half of the enamel. \\
\hline $\mathbf{4}$ & Dye penetration into the dentin without extending into the pulpal wall. \\
\hline
\end{tabular}

After measuring of gap formation along the margin of restoration, one random specimen from each group was scanned under scanning electron microscope to examine resin-dentin interfaces at magnifications X1500 to demonstrate the tooth/restoration interface. The values of mean and standard deviation (SD) were tabulated, illustrated graphically and statically analyzed. Regression model using three-way Analysis of Variance (ANOVA) was used to test the significance of the effect of adhesive system, storage period and their interactions on mean gap area. Tukey's post-hoc test was used for pair- 
wise comparisons between the groups when ANOVA test is significant. The significance level was set at $P \leq 0.05$.

\section{Results:}

At the occlusal and gingival margins, self-etch adhesive system showed statistically significant higher mean gap area than Total-etch adhesive system and six months period showed the statistically significant highest mean gap area. There was no statistically significant difference between 1 day and 3 months periods; both showed statistically significantly the lowest mean gap area values respectively. Table (2) Figure (1).

Scanning Electron Microscope Observation in Figure (2) showed hybrid layer with short resin tags created by the self-etch adhesive system with few areas of adhesive failure after 3 months storage period.

\section{Table (2)}

Mean occlusal and gingival gap area $(\mu \mathrm{m})$, standard deviation and $\mathrm{p}$-value of all variable interactions

\begin{tabular}{|c|c|c|c|c|c|c|c|c|}
\hline \multicolumn{2}{|l|}{ Storage Time } & \multicolumn{2}{|l|}{1 day } & \multicolumn{2}{|c|}{3 months } & \multicolumn{2}{|c|}{6 months } & \multirow[t]{2}{*}{$P$-value } \\
\hline Adhesive & Margin & Mean & SD & Mean & SD & Mean & SD & \\
\hline \multirow[t]{2}{*}{ Total etch Adhesive } & Occlusal & $26.4^{\mathrm{a}}$ & 5.2 & $25.6^{a}$ & 3.6 & $33.4^{b}$ & 6.9 & \multirow[t]{4}{*}{$<0.001^{\star}$} \\
\hline & Gingival & $47.3^{a}$ & 7.5 & $54.5^{\mathrm{b}}$ & 8 & $94.5^{c}$ & 9.7 & \\
\hline \multirow[t]{2}{*}{ Self-etch Adhesive } & Occlusal & $31.6^{\mathrm{b}}$ & 4.2 & $36.1^{\mathrm{b}}$ & 5.2 & $58.3^{c}$ & 7.3 & \\
\hline & Gingival & $52.8^{\mathrm{b}}$ & 6 & 61. b & 3.4 & $104^{d}$ & 6.9 & \\
\hline
\end{tabular}

*: Significant at $P \leq 0.05$, Means with different letters are statistically significantly different according to Tukey's test

\section{Discussion:}

The interfacial distance between the eluted restoration and the tooth structure is known as marginal adaptation. Excellent marginal adaptation depends on the quality of the composite resin and the adhesive system used. Marginal imperfection may occur at the area of gap formation which may lead growth of bacteria, secondary caries, and pulp damage. ${ }^{(9)}$ Getting optimal marginal seal during composite resin placement influence on tooth tissues protection against microleakage. ${ }^{(10)}$ Microleakage is related to the polymerization shrinkage that results in stresses at the tooth restoration interface and it ranges from $2.6-7.1 \% .{ }^{(11)(12)}$ which affects the bond and lead to gap formation. Hence, appropriate bonding of the adhesive to the tooth structure contributes to prevent marginal microleakage. ${ }^{(11)}$ Enamel bonding is a simple process when compared to dentin bonding which presents a great challenge in the 
dental clinics due to the heterogenous structure of the dentin. ${ }^{(13)}$ The presence of nanofillers in the nanofilled adhesive systems may decrease the shrinkage of the adhesive, thus reduce the occurrence of microleakage. ${ }^{(14)}$ The reduced score of microleakage was observed with nanofilled adhesives as the collagen fibril network filters out the nanofillers, holding them at the hybrid layer surface which act as an intermediate shock absorber. ${ }^{(15)}$ The results of this study showed that self-etch adhesive had statistically significant higher mean gap area in both occlusal and gingival margins than total-etch adhesive. This could be related to the difference in the action mechanism between self-etch and total etch adhesives. Total etch adhesives result in resin tags formation on both etched enamel and dentin surfaces with total elimination of the smear layer by using a strong phosphoric acid. In dentin, phosphoric acid dissolves the mineral completely, so the adhesion depends on diffusion and infiltration of the resin within the exposed collagen fibril of dentin. ${ }^{(4)}$ On the other hand, the self-etch adhesives resulted in deep demineralization effects especially with strong (highly acidic) adhesives and this bonding mechanism of "strong" self-etch adhesives is diffusion-based, like the etch and rinse adhesive. ${ }^{(4)}$ The acid in the self-etch adhesive dissolves the smear layer and demineralizes the underlying dentin but the demineralization is self-limited since the acidity of the monomers are gradually buffered by the dentin mineral content. In conclusion, the resultant morphological aspect of the bonded interface is affected by two main factors, the dentin structure, and the aggressiveness of the acidic monomers. ${ }^{(16)}$ Low-pH self-etch adhesives have been reported with low bond strength values, particularly at dentin ${ }^{(17)}$ with residual solvent (water) that remains at the adhesive interface, which can hardly be totally eliminated. ${ }^{(4)}$ This was agreed with Gupta et al.,(16) and Gueders et al.,(18) who proved that the self-etch adhesive systems are less effective when compared to total etch adhesive systems, suggesting that their high acidity appears to drastically weaken the bonding performance. Also, self-etch agents comprises of acidic monomers, which get activated in the presence of water and begins the occurrence of demineralization. In addition, the products of demineralization are still present in the hybrid layer. Hence, mechanical adhesion occurred with sudden transition of the exposed collagen fibril network to the underlying unaffected dentin. This agreed with Owen et al., ${ }^{(19)}$ who found that the use of self-etch adhesives increased the microleakage in the restorations because of the incomplete etching of the enamel surface by acidic monomer which resulted in high values when compared to the etch and rinse adhesives. Geerts et al., ${ }^{(20)}$ compared different types of adhesive systems and stated that the total etch adhesive systems used had the least leakage and they concluded that the total etch adhesives had superior results than the self-etch adhesives. The results in our study was not agreed with Osorio et al., ${ }^{(21)}$ who examined the marginal leakage of different adhesive systems in Class $\mathrm{V}$ composite resin restorations. They proved that the self-etch adhesives had similar marginal integrity on enamel and better marginal integrity on dentin when compared to the conventional conditioning of the enamel. This could be related to the $\mathrm{C}$-factor difference as they did class $\mathrm{V}$ cavities and in our study was did class II cavities. In another study by Takahashi et al., (22) they found an excellent result of the self-etch adhesive system at the dentin interface when compared to etch and rinse adhesive system. This could be related to the difference in the chemical composition as stated by Hayakawa et al., (23) who found excellent bonding results when they used self-etching primers containing 10-MDP. 10-MDP results in minimal dissolution of the smear plugs with limited tubules opening which reduces dentin 
permeability and facilitates the penetration, impregnation, polymerization, and entanglement of the monomers with demineralized dentin to form a relatively thick hybrid layer. ${ }^{(24)} 10-M D P$ also has two hydroxyl groups which may chelate to the calcium particles in enamel and dentin. ${ }^{(25)}$ Until today, etch and rinse technique proved it is value in the bonding at the dentin restoration interface ${ }^{(26)}$ and our results in this study agreed with this. Also, the results showed that the sealing of the occlusal margins were better than the gingival margins. This could be related to the presence of high organic component, tubular configuration, fluid pressure and the lower surface energy of dentin which makes bonding to enamel more stable. ${ }^{(27)}$ Another explanation is the polymerization shrinkage which cannot be compensated with water sorption and stress relaxation. ${ }^{(16)}$ The results of this study showed that six months period had statistically significantly the highest mean gap area in both occlusal and gingival margins. There was no statistically significant difference between 1 day and 3 months periods; both showed the statistically significantly lowest mean gap area values. Also, the teeth restored with both adhesive systems had increased microleakage at occlusal and gingival margins at 6 months. This could be related to the water absorption with time in the polymer network which will result in hydrolytic degradation of the adhesive. (28)(29) This is agreed with other researches that referred the decrease in marginal adaptation to the water penetration in the resin tooth interface and the hydrolysis of the bond. Hydrolysis may occur because of resin or collagen degradation. ${ }^{(30)}$ Hashimoto et al., ${ }^{(31)}$ stated that the hydrolytic degradation of the bond can affects the bond efficacy (bond strength and marginal seal) on the long run. Another cause of the high gap formation after 6 months storage is related to the presence of 10-20\% HEMA in the composition of the dental adhesives which penetrates the demineralized dentin and improves the wettability of the adhesive. ${ }^{\left({ }^{32}\right)}$ The hydroxyl group in the dental adhesives increase the water sorption of the adhesive which may result in drop in the bond strength in the long term. So, the stresses initiated at the dentin resin interface which pulls the collagen fibers in the hybrid layer and resin resulting in a tear along the bonded interface as the collagen fibers become weaker over time from hydrolysis. ${ }^{(32)}$ This was agreed with torkabadi et al., ${ }^{(33)}$ who evaluated the durability of a HEMA free single step adhesive (G bond) and a HEMA containing adhesive (Tri-s-bond) after one year storage in water and they proved significant reduction in bond strength to dentin in HEMA containing group. This was agreed with Mousavinasab et al., ${ }^{(27)}$ who found high microleakage at 6 months storage compared to one day when two adhesive systems were used (single bond and one step self-etch). They related their results to the concentration of HEMA in the bonding system. Hence, water sorption and adhesive solubility are important factors in the durability of the restoration. Yiu et al., ${ }^{(34)}$ evaluated the effect of copolymer hydrophilicity on water sorption and solubility characteristics on bond durability and they stated that water sorption plays a major role in the bond efficacy and subsequently the bond durability. water molecules diffuse into the polymer matrices by binding effectively to the polar sites via hydrogen bonding. In this study, there was no significant differences at one day and three months storage periods and this could be related to the insufficient time essential for detection any changes in the polymer network and its degradation to occur within the hybrid layer. These results agreed with Sadek et al., (35) who stated that 24 hours and 3 months storage period had no effect on microleakage of Single Bond to dentin. Also, Radovic et al., ${ }^{(36)}$ in their study stated that 3 months storage period was not enough to start 
degradation of the bond and microleakage. Another study conducted by Li et al., (37) proved that after 6 months storage period the differences on microleakage results starts to appear.

\section{Conclusions}

Total-etch adhesive system enhances the marginal adaptation compared to self-etch adhesive system and storage of composite resin in water has adverse effect on the marginal adaptation to all groups with time.

\section{Abbreviations}

HEMA

Hydroxy Ethyl Meta Acrylate.

10-MDP

Methacryloyloxydecyl Dihydrogen Phosphate

\section{Declarations}

\section{Ethics approval and consent to participate:}

Ethics approval was obtained from the Research Ethical Committee, Al-Farabi Private Colleges in Jeddah (Approval No20-03/8), and written informed consent was obtained from the donors.

\section{Consent to publish:}

Not applicable

\section{Availability of data and materials:}

The datasets used and/or analyzed during the current study are available from the corresponding author on reasonable request.

\section{Competing interests:}

The authors declare that they have no competing interests.

\section{Funding:}

Self-funded. This research did not receive any financial support.

\section{Authors' contributions:}

EA designed the study and performed the experiments and collected the data and wrote and revise the manuscript. 
Acknowledgements:

Not Applicable

\section{Corresponding Autor:}

Ebaa Ibrahim Alagha.

Assistant Professor of Operative Dentistry, Restorative Department, Faculty of Dentistry, Al-Farabi Private Colleges, Jeddah, KSA.

\section{Authors' information:}

\section{Ebaa Ibrahim Alagha.}

Department of Restorative Dentistry, Al-Farabi Private Colleges, Faculty of Dentistry, Jeddah, Saudi Arabia.

Address: 4438 Abdul Aziz Alqubaysi- Almarwa Jeddah, KSA

Phone number: 00966542253510

E-mail address: drebaaialagha@gmail.com

\section{References}

1. Demarco F, Kullaris K, Korrea M, Cenci M, Moraes R, Opdam N. Should my composite restorations last forever? Why are they failing? Braz Oral Res. 2017; 31(1).

2. Majety K, Pujar M. In vitro evaluation of microleakage of class II packable composite resin restorations using flowable composite and resin modified glass ionomers as intermediate layers. $\mathrm{J}$ Conserv Dent. 2011;14(4):414-7.

3. Mosharrafian S, Heidari A, Rahbar P. Microleakage of Two Bulk Fill and One Conventional Composite in Class II Restorations of Primary Posterior Teeth. J Dent (Tehran). 2017;14(3):132-31.

4. Van Meerbeek B, De Munck J, Yoshida Y, Inoue S, Vargas M, Vijay P. Buonocore Memorial Lecture. Adhesion to enamel and dentin: current status and future challenges. Oper Dent. 2003; (28)3: 21535 .

5. Van Meerbeek B, Perdigao J, Lambrechts P, Vanherle G. The clinical performance of adhesives. J Dent. 1998;26(1):1-20.

6. Tayel D, El-Sharkawy M, Mahmoud E. Microleakage of class II composite restorations with different restorative techniques (an invitro study). Alex Dent J. 2016: 41.138-45.

7. Hasani Z, Khodadadi E, Ezoji F, Khafri S. Effect of Mechanical Load Cycling on Microleakage of Restorative Glass lonomers Compared to Flowable Composite Resin in Class V Cavities. Front Dent. 
2019;16(2):136-43.

8. Jawaed N, Abidi S, Qazi F, Ahmed S. An in-vitro evaluation of microleakage at the cervical margin between two different class II restorative techniques using dye penetration method. J Coll Physicians Surg Pak. 2016;26(9):748-52.

9. El-Nawawy M, KoraitiM L, Abouelatta O, Hegazi H. Marginal Adaptation of Nanofilled, Packable and Hybrid Dental Composite Resins Stored in Artificial Saliva. Am J Bio Eng. 2012;2(3):105-14.

10. Orłowski M, Tarczydło B, Chałas R Evaluation of Marginal Integrity of Four Bulk-Fill Dental Composite Materials: In Vitro Study. Sci Wor J. 2015; 2015: 701262.

11. Braga R, Ballester R, Ferracane J. Factors involved in the development of polymerization shrinkage stress in resin-composites: a systematic review. Dent Mater. 2005;21(10):962-70.

12. Bagis $Y$, Baltacioglu $H$, Kahyaogullari S. Comparing microleakage and the layering methods of silorane-based resin composite in wide class II MOD cavities. Oper Dent. 2009;34(5):578-85.

13. Roberson T, Heymann H, Swift E Art and science of operative dentistry. 5th edition. St. Louis, Missouri, Elsevier Inc, 2006.

14. Deliperi S, Bardwell D, Papathanasiou A, Perry R. Microleakage of resin-based liner materials and condensable composites using filled and unfilled adhesives. Am J Dent. 2003;16(5):351-5.

15. Deliperi S, Bardwell D, Wegley C. Restoration Interface Microleakage Using One Total-etch and Three Self-etch Adhesives. Opera Dent. 2007;32(2):179-84.

16. Gupta A, Tavane P, Gupta P, Tejolatha B, Lakhani A, Tiwari R, et al. Evaluation of microleakage with total etch, self-etch and universal adhesive systems in class $\mathrm{V}$ restorations: an in vitro study. J Clin Diag Res. 2017;11(4):53-6.

17. Inoue S, Vargas M, Abe Y, Yoshida Y, Lambrechts P, Vanherle G, Sano H, Van Meerbeek B. Microtensile bond strength of eleven contemporary modern adhesives to dentin. J Adhes Dent. 2001;3(3):237-45.

18. Gueders A, Charpentier J, Albert A, Geerts S. Microleakage after thermocycling of 4 etch and rinse and 3 self-etch adhesives with and without a flowable composite lining. Oper Dent. 2006;31(4):4505.

19. Owens B, Johnson W, Harris E. Marginal Permeability of Self-etch and Total-etch Adhesive System. Oper Dent. 2006;31(1):60-7.

20. Geerts S, Bolette A, Seidel L, Gueders A: An in vitro evaluation of leakage of two etch and rinse and two self-etch adhesives after thermocycling. Int J Dent. 2012; 2012:852841.

21. Osorio R, Toledano M, de Leonardi G, Tay F. Microleakage and interfacial morphology of self-etching adhesives in Class $\mathrm{V}$ resin composite restorations. J Biomed Mater Res B Appl Biomater. 2003;66(1):399-409.

22. Takahashi R, Nikaido T, Tagami J, Hickel R, Kunzelmann K. Contemporary adhesives: marginal adaptation and microtensile bond strength of Class II composite restorations. Am J Dent. 2012;25(3):181-8. 
23. Hayakawa T, Kikutake K, Nemoto K. Influence of self-etching primer treatment on the adhesion of resin composite to polished dentin and enamel. Dent Mater. 1998;14(2):99-105.

24. Jackson W, Soderholm K. Comparison of shear and flexural bond strength tests versus failure modes of dentin bonding systems. Am J Dent. 2001;14(5):297-303.

25. Kubo S, Yokota H, Sata Y, Hayashi Y. Microleakage of self-etching primers after thermal and load cycling. Am J Dent. 2001;14(3):163-9.

26. Ernst $C, K$ "otter T, Victor A, Canbek K, Brandenbusch M, Willershausen B. Marginal integrity of selfetching and total etching adhesives in two different application protocols. J Adhes Dent. 2004;6(1):25-32.

27. Mousavinasab S, Atai M, Alavi B. To compare the microleakage among experimental adhesives containing nanoclay fillers after the storages of 24 hours and 6 months. The Open Dent $\mathrm{J}$. 2011;29(5):52-7.

28. De Munck J, Van Meerbeek B, Yoshida Y, Inoue S, Vargas M, Suzuki K, et al. Four-year water degradation of total-etch adhesives bonded to dentin. J Dent Res. 2003;82(2):136-40.

29. Osorio R, Monticelli F, Moreira MA, Osorio E, Toledano. M:Enamel-resinbonddurability of self-etch and etch\&rinse adhesives. Am J Dent. 2009;22(6):371-5.

30. De Munck J, Van Landuyt K, Peumans M, Poitevin A, Lambrechts P, Braem M, et al. A critical review of the durability of adhesion to tooth tissue: methods and results. J Dent Res. 2005;84(2):118-32.

31. Hashimoto M, Fujita S, Kaga M, Yawaka Y. In vitro durability of one-bottle resin adhesives bonded to dentin. Dent Mater J. 2007;26(5):677-86.

32. Van Landuyt K, Snauwaert J, Peumans M, De Munck J, Lambrechts P, Van Meerbeek B. The role of HEMA in one-step self-etch adhesives. Dent Mater. 2008;24(10):1412-9.

33. Torkabadi S, Nakajima M, Ikeda M, Foxton R, Tagami J. Bonding durability of HEMA-free and HEMAcontaining one-step adhesives to dentine surrounded by bonded enamel. J Dent. 2008;36(1):80-6.

34. Yiu C, King N, Carrilho M, Sauro S, Rueggeberg F, Prati C. Effect of resin hydrophilicity and temperature on water sorption of dental adhesive resins. Biomaterials. 2006;27(9):1695-703.

35. Sadek F, Moura S, Ballester R, Muench A, Cardoso P. The effect of long-term storage on the microleakage of composite resin restorations: qualitative and quantitive evaluation. Pesqui Odontol Bras. 2003;17(3):261-6.

36. Radovic I, Vulicevic ZR, Garcia-Godoy F. Morphological evaluation of 2- and 1-step self-etching system interfaces with dentin. Oper Dent. 2006;31(6):710-8.

37. Li H, Burrow M, Tyas M. The effect of long-term storage on nanoleakage. Oper Dent. 2001;26(6):609-16.

\section{Figures}




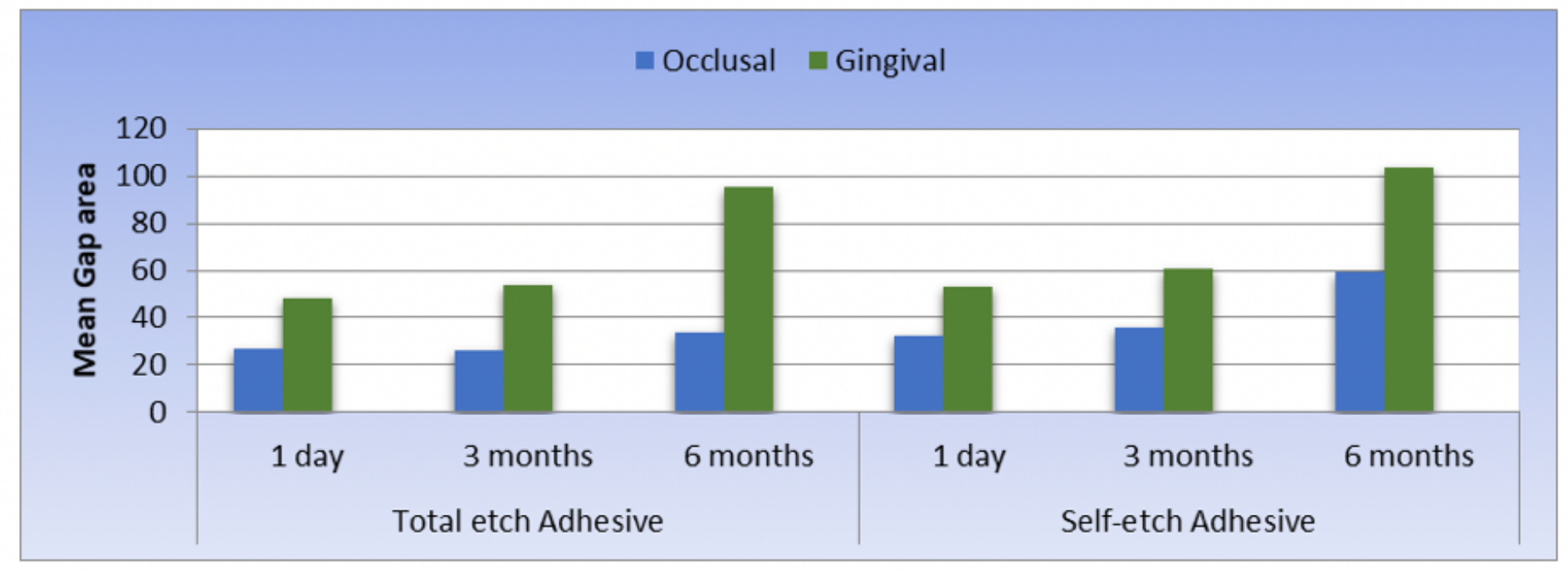

\section{Figure 1}

Bar chart showing the difference in mean gap areas among all groups.

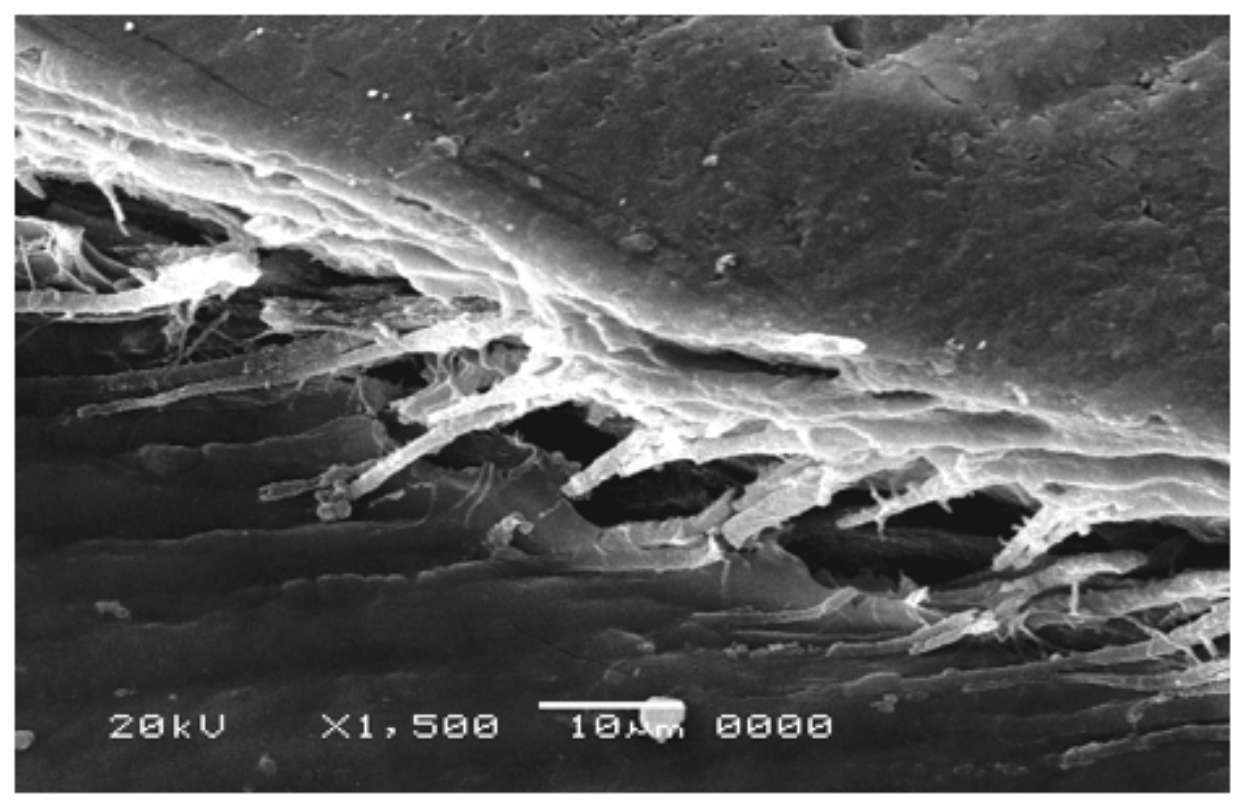

\section{Figure 2}

SEM showed hybrid layer with short resin tags created by the self-etch adhesive system with few areas of adhesive failure after 3 months storage period. 